\title{
Packaging Problem Identified
}

National Cancer Institute

\section{Source}

National Cancer Institute. Packaging Problem Identified. NCI Thesaurus. Code C92094.

Problems that occurred because of the device packaging. 